\title{
Multiple flooding events in Martian outflow channels
}

\author{
Keith P. Harrison ${ }^{1}$ and Robert E. Grimm ${ }^{1}$ \\ Received 6 June 2007; revised 18 September 2007; accepted 29 October 2007; published 6 February 2008.
}

[1] The large outflow channels of Chryse Planitia, Mars, are thought to have been carved by floodwaters discharged from an aquifer beneath a confining cryosphere. However, conventional models of groundwater flow require optimistically high permeabilities to produce, in a single flooding event, the discharge rates and volumes inferred from channel morphology. Additionally, discharge likely ceased upon refreezing of chaotic terrain fractures carrying it to the surface, further limiting the volume of water produced in a single flood. It is thus probable that multiple surface discharge events were required, and we quantify this hypothesis with regional groundwater simulations. Each discharge event is triggered by cryosphere disruption due to superlithostatic hydraulic head at the channel source region and is terminated by cryosphere fracture refreezing. Before the next event, head is allowed to recover with the aid of distal aquifer recharge constrained by previous global groundwater models. Our baseline model, which emulates the source region of Kasei Valles, yields a minimum of 2900 flooding events even for high depth-averaged aquifer permeabilities corresponding to near-surface values of $10^{-9} \mathrm{~m}^{2}$. Although fewer events are required for other circum-Chryse channels, formation by a single flood remains improbable. We suggest that unrealistically high numbers of floods may be circumvented by an alternative model involving the local ponding of surface discharge to form standing bodies of water. Episodic failure of these bodies produces flood outbursts which erode the channels.

Citation: Harrison, K. P., and R. E. Grimm (2008), Multiple flooding events in Martian outflow channels, J. Geophys. Res., 113, E02002, doi:10.1029/2007JE002951.

\section{Introduction}

[2] The large Hesperian outflow channels of Mars, thought to be formed by the catastrophic surface discharge of groundwater from confined aquifers [Baker, 1979; Carr, 1979], present a challenge to the canonical view of groundwater flow. This view dictates relatively slow, diffusive flow of water through small interconnected pore spaces in the crust and is not easily reconciled with the high volumes and rates of discharge inferred from outflow channel morphology. As suggested by Carr [1979] and later by Manga [2004], groundwater flow may meet peak discharge rate requirements over the course of a single flooding event only if crustal permeabilities are at the upper limit of the terrestrially observed range, about $10^{-9} \mathrm{~m}^{2}$. Multiple floods thus seem likely [Hanna and Phillips, 2003; Manga, 2004] but few numerical constraints exist [Andrews-Hanna and Phillips, 2007]. Physical constraints provided by analysis of geologic units [Scott, 1993; Tanaka and Skinner, 2004; Glotch and Christensen, 2005] and observation of inner channels [e.g., Williams and Malin, 2004; Coleman, 2005] also suggest multiple floods but possible erasure of early events makes the total number difficult to infer. Our goal

\footnotetext{
${ }^{1}$ Southwest Research Institute, Boulder, Colorado, USA.
}

Copyright 2008 by the American Geophysical Union. 0148-0227/08/2007JE002951\$09.00 here is to determine mutual constraints on the permeability, number, and duration of flooding events required.

[3] Multiple events involve two distinct groundwater flow regimes. The first consists of transient, local drawdown producing aquifer discharge and attendant surface flooding, and the second consists of a recovery mechanism allowing hydraulic heads to be restored between floods. This latter process requires an influx of groundwater from more distal parts of the aquifer and is therefore active on a larger scale than the transient flooding event. Large scale groundwater flow associated with outflow channels was investigated by Harrison and Grimm [2004]. In these models, it was assumed that growth of ice sheets during periods of high planetary obliquity could lead to the infiltration of basal meltwater into the crust, thereby recharging the aquifer. To constrain the effects of recharge, we simulated a global Martian aquifer with a groundwater source at either the Tharsis rise or the south polar region and sinks at outflow channel source regions. Our conclusion was that Tharsis recharge could provide a relatively efficient supply of groundwater to the outflow channels. However, we assumed that outflow channel sources were able to discharge groundwater continuously as long as it was available. Continuous discharge represented the time-averaged effect of multiple discrete flooding events: the resulting groundwater flow therefore captured the large-scale flow pattern that, while sensitive to the large accumulated loss of water from the outflow sources, was not sensitive to short-lived 
localized drawdown dynamics. Although the low, globally averaged permeability of these models does not permit large short-term flooding events, higher permeabilities occurring as local- and regional-scale fluctuations about this mean are likely to make such events possible.

[4] Here we switch focus from global flow to local-toregional flow attending transient flooding events. Our new models are implicitly embedded in global models: they are separate high-resolution regional models with boundary conditions inherited from global model results. In terms of the terminology used above our regional model focuses on the transient groundwater regime and is placed in the context of a large-scale recovery mechanism.

[5] In selecting observational constraints for our models we avoid the use of inferred peak discharge rates because our numerical models, like those of Carr [1979], can be made to yield arbitrarily high-peak discharge rates regardless of permeability, simply by decreasing initial time steps and increasing spatial resolution. This is due to the prescribed initial step change in head across the source region boundary, which (theoretically) yields an infinite head gradient and therefore infinitely rapid flow. Consequently, the relationship between peak discharge rate and permeability is nonunique and an additional constraint must be applied: in most cases this is a somewhat arbitrary time interval (1 hour for Carr [1979]). This provides a lower boundary on permeability, defined as that value which results in model discharge just exceeding the required rate over the chosen time interval.

[6] Discharge volume, rather than rate, deserves further consideration because it is closely related to limitations on aquifer size and the required number of flooding events. We thus choose discharge volume as our principal observational constraint. When integrated over periods of days and longer, discharge volume does not depend strongly on the size of initial time steps or spatial resolution (the very high-discharge rates at early times do not last long enough to contribute significant volumes of water). It also has physically realistic upper limits imposed by the model itself through either the available storage or the rate of aquifer recharge. Finally, discharge volume has (like the discharge rate) observational limits imposed by channel morphology, namely the excavated sediment volume. This volume must be converted to a fluid volume using an appropriate choice of sediment-to-water ratio (S/W). A high-S/W value will minimize the number of flooding events required, and this is the approach we take with our nominal model. Even with high $\mathrm{S} / \mathrm{W}$ it is likely that multiple regional pore volumes must be discharged in order to incise the circum-Chryse outflow channels and recharge is thus required [Harrison and Grimm, 2004].

\section{Model}

[7] Our regional model simulates groundwater flow attending outflow channel discharge as depicted by the conceptual model of Figure 1a. We use MODFLOW (a well-established finite difference groundwater code from the U.S. Geological Survey) [Harbaugh et al., 2000] to simulate a confined aquifer containing a circular outflow channel source region where groundwater discharges to the surface. Chaotic terrain is assumed to cap the source region (a)
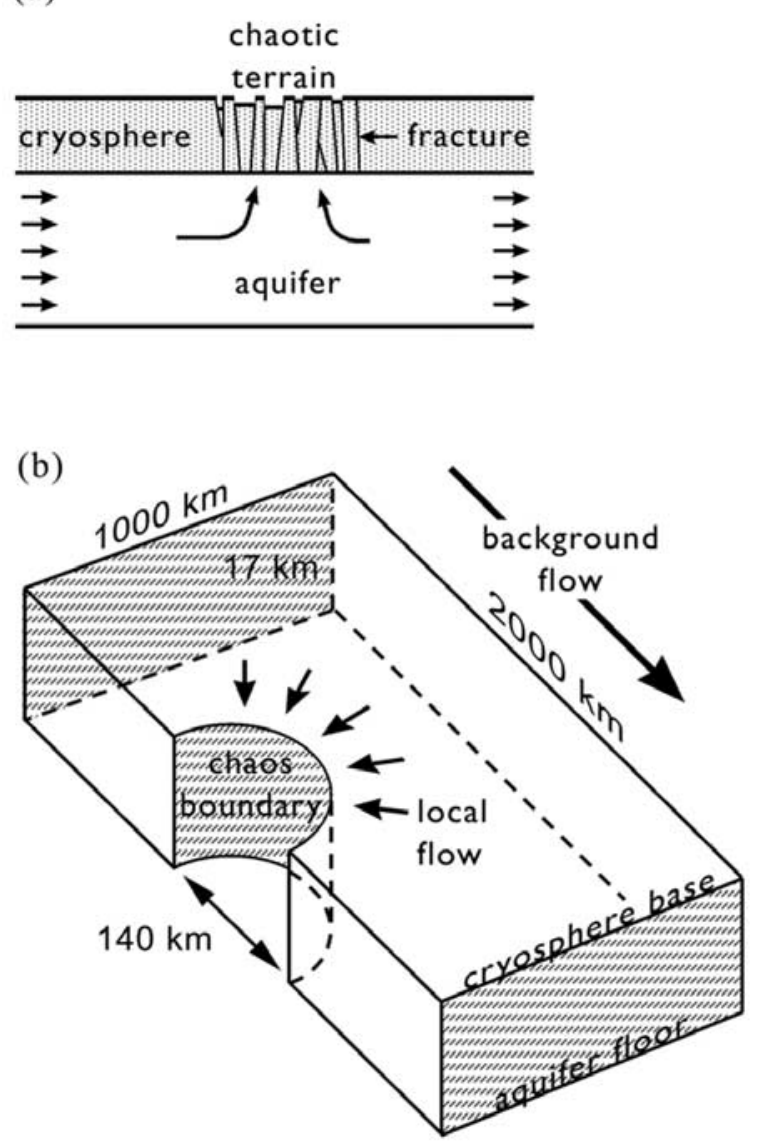

Figure 1. (a) Conceptual model. Groundwater discharges from an outflow channel source region consisting of fractures in a confining cryosphere. Associated flow in the aquifer is superimposed on a uniform background flow. (b) MODFLOW aquifer embodying conceptual model. Because a single layer is used, no vertical flow is considered, and the part of the aquifer under the source region is not modeled explicitly. Hydraulic head is fixed along the boundary of the source region (curved hatched area). Groundwater flux is fixed along opposite distal boundaries (planar hatched areas), providing background flow. Between discharge events, head at the chaos boundary is allowed to recover. Remaining boundaries are no flow, and on the side of the source region this condition creates a symmetry axis so that only half of the source region and its neighborhood need be modeled explicitly.

(Figure 1b) but is not modeled explicitly. Model symmetry requires that only half of the source region and its neighborhood need to be modeled. Because of computational constraints arising from the large number of simulations needed, we model the aquifer with a single layer. Consequently, aquifer permeability and porosity are equivalent to depth-averaged values. Modeling a single layer also implies that vertical flow is ignored and discharge rates are thus measured through the walls of an imaginary cylinder projected vertically downward through the aquifer from the circular source region boundary in the same way as Carr's model [1979]. The cylindrical surface is half the size 
of the horizontal circular surface and early discharge rates (when flow would be mostly vertical in a fully threedimensional (3-D) model) might thus be underestimated by a similar factor. As seen in section 3, this discrepancy is not likely to influence our conclusions.

[8] Boundary conditions are quantitatively constrained by Mars Global Surveyor Mars Orbiter Laser Altimeter (MOLA) topography and by steady state results of the Harrison and Grimm [2004] global models, as follows. Our nominal model (Figure 1) is based on Echus Chasma, the apparent source region of Kasei Valles. The Echus Chasma floor provides both the source region radius $(70 \mathrm{~km})$ and fixed hydraulic head $(-1000 \mathrm{~m})$. The distance from source region center to distal model boundaries is the distance between Echus Chasma and the edge of the Tharsis recharge zone used by Harrison and Grimm [2004] models. Although the nominal recharge zone used by Harrison and Grimm [2004] may realistically have been larger (it was set to have an area equal to that of an alternative south polar recharge zone), its nominal size results here in a generous regional model radius of $1000 \mathrm{~km}$. The significance of model size is discussed in depth in section 3.3.1. The minimum finite difference cell size in the regional model is $1.5 \mathrm{~km}$ (compared to $120 \mathrm{~km}$ in the global model).

[9] A uniform 1-D background flow is applied to the regional model through fixed flux boundary conditions at two opposite distal boundaries. We use a value of $0.11 \mathrm{~m}^{3} / \mathrm{s}$ (or $3.4 \times 10^{-12} \mathrm{~m} / \mathrm{s}$ ), determined by the global model flow rate averaged over the area occupied by the regional model. Initial head close to the source region $(4600 \mathrm{~m})$ is the mean of global model heads $1000 \mathrm{~km}$ upstream and $1000 \mathrm{~km}$ downstream and is close to the lithostatic value $(5000 \mathrm{~m})$. Given the background flow, the initial head near the source region, and a chosen depth-averaged aquifer permeability $k$, the initial heads in the remainder of the regional model are fully determined. When considering a range of $k\left(10^{-15}\right.$ $10^{-9} \mathrm{~m}^{2}$ ), the initial regional head gradients are adjusted inversely such that the initial background flux always matches that imposed at the boundaries. If drawdown due to source region discharge reaches the regional model boundary, heads throughout the model will begin to drop and discharge rates will fall steeply. Aquifer porosity is fixed at 0.02: a mean of depth-averaged values obtained from exponential [Binder and Lange, 1980; Clifford, 1993], permeability-dependent [Saar and Manga, 1999; Harrison and Grimm, 2004], and mega-regolith [Hanna and Phillips, 2005] formulations. We use a confined storage coefficient of $1.6 \times 10^{-2}$, derived from a depth-averaged rock matrix compressibility of $2.5 \times 10^{-10} \mathrm{~Pa}^{-1}$ [Hanna and Phillips, 2005].

[10] Implicit in the model is the assumption that a cryosphere confines the aquifer everywhere except at the outflow channel source region where cryosphere fractures carry groundwater to the surface. Discharge continues until the cryosphere fractures refreeze, forming a complete seal over the aquifer [Andrews-Hanna and Phillips, 2007]. We do not model cryosphere fractures explicitly but use parameterizations of turbulent and laminar fracture flow to calculate the appropriate shutoff discharge rate $Q_{s}$ at which fractures refreeze (appendix A), and we confirm that discharge reaches the surface before this threshold is met (appendix B). Once discharge has ceased, the model is set up for a recovery phase. Fixed head conditions at the source region boundary are exchanged for no flow, allowing source region heads to recover. However, recovery will not occur unless desired distal boundary heads are imposed (fixed flux at the distal boundaries will enforce a head gradient, not absolute head values). We thus exchange fixed flux boundary conditions at the distal model boundaries with fixed heads from the global model. The recovery phase is terminated when source region heads reach $98 \%$ of their initial value. Although we have not conducted a detailed sensitivity study on this choice of threshold, experiments with values between 95 and $99 \%$ produce similar results. Note also that recovery times are somewhat underestimated because groundwater can be drawn through the distal boundary at a rate exceeding that provided by the global model. To mitigate this effect, we set outer boundary permeabilities to the global model value of 6 $\times 10^{-16} \mathrm{~m}^{2}$. Once recovery is complete, cryosphere failure is ready to occur again and a similar discharge-recharge cycle ensues (i.e., no further modeling is required). Cycles are repeated as many times as necessary to produce the cumulative discharge volume required for channel formation. The entire process is repeated for a range of $k$ and $Q_{s}$.

[11] Although our model is constrained by Echus Chasma morphometry, it is intended to represent the general structure of any circum-Chryse outflow channel formed through the catastrophic discharge of groundwater at zones of chaotic terrain. We consider different source regions and channel volumes by varying key model dimensions and required discharge volumes as described in section 3.3.3.

\section{Results}

\subsection{Discharge Rate}

[12] The basic output of our model is the volumetric discharge rate from the outflow channel source region as a function of time, indicated for different permeabilities in Figure 2 . Discharge rate initially matches closely the analytic solution to flow at a finite radius well with constant drawdown [Lohman, 1972]. Although this solution does not account for a background head gradient, the gradient in our models is small enough to have negligible effect on initial well discharge. The analytic solution is therefore most useful in computing early discharge rates driven by head gradients too steep to be resolved numerically. As time progresses, drawdown due to source region discharge spreads radially outward and eventually reaches the distal model boundary.

[13] Further expansion of the drawdown cone is attenuated by the relatively low depth-averaged permeability of the surrounding global-scale aquifer. (As noted above, relatively high regional permeabilities are needed for large transient flooding events.) This attenuation causes a steep dropoff in source region discharge rates (Figure 2). Before this final dropoff each discharge rate curve begins to depart from its initial steep power law (Figure 2) toward a second, shallower power law. This behavior is explained in terms of the relative dimensions of the chaos region and the expanding drawdown cone surrounding it. At early times, drawdown extends only a short distance from the chaos boundary and the curvature of the boundary has negligible 


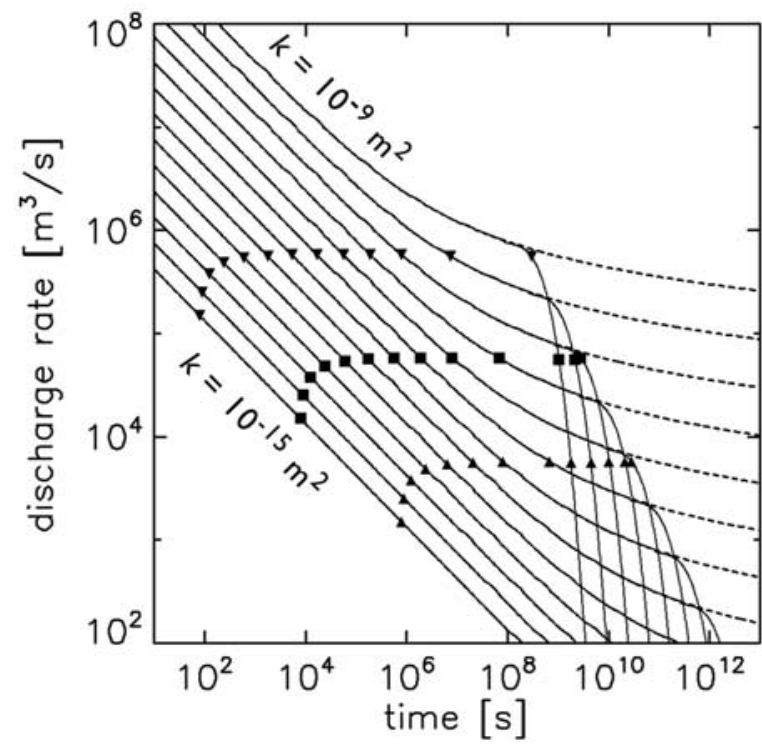

Figure 2. Discharge rate versus time for a range of aquifer permeabilities $k$. Successive permeabilities are spaced at two points per decade. Curves follow a power law as long as the radial extent of drawdown is small compared to the chaos radius. As drawdown expands, the flow becomes 2-D and discharge rate begins to transition to a second, shallower power law. For a laterally unlimited aquifer of homogeneous permeability, discharge would continue along the dashed lines. However, for a finite aquifer bounded by relatively low global-scale permeabilities, discharge rate begins to drop steeply once drawdown reaches the aquifer boundaries. The shut-off discharge rate $Q_{s}$ due to cryosphere refreezing (indicated by the squares) is the same for all high $k$ values but is reached at later times as $k$ increases. A downturn in $Q_{s}$ occurs at lower $k$ (appendix A). Triangles indicate an order of magnitude variation on either side of $Q_{s}$.

effect (flow is essentially 1-D). At later times, drawdown has expanded outward far enough to become comparable in size to the chaos radius and flow is 2-D.

Figure 3. (a) Volume of water produced by a single flooding event as a function of depth-averaged aquifer permeability k. Each dotted curve in the background corresponds to a unique shut-off discharge rate $Q_{s}\left(\mathrm{~m}^{3} / \mathrm{s}\right)$ as indicated by the superimposed numbers. The hatched region represents feasible models, namely those with $Q_{s}$ derived from nominal cryosphere fracture refreezing calculations (thick line through centre of region) with an order of magnitude added in each direction. The hatched region boundaries follow lines of constant $Q_{s}$ except for a departure at low $k$, corresponding to the downturn in $Q_{s}$ in Figure 2, and at high $k$, corresponding to the constraints of hydrologic connectivity. The vertical dotted line indicates the maximum likely $k$. (b) Duration of a single flooding event. (c) Duration of a complete flood-recovery cycle. Recovery generally takes considerably longer than flooding. (d) Minimum number of floods required to produce enough water for channel erosion. At high $k$, where the lowest numbers of floods are required, flood duration is greater than 10 years.

\subsection{Cumulative Discharge and Duration of a Single Flooding Event}

[14] Our analysis of fracture freezing (appendix A) shows that the shut-off discharge rate $Q_{s}$ is constant $\left(5.7 \times 10^{4} \mathrm{~m}^{3} / \mathrm{s}\right)$ for medium to high $k$. Nonetheless, this value corresponds to a wide range of shut-off times (Figure 2) and thus to a similarly wide range of cumulative discharge volumes for a single flooding event (Figure 3a).

[15] Cumulative discharge increases with $k$ as a power law at low $k$ (while flow is 1-D) but at higher $k$ begins to increase more rapidly toward a steeper power law (flow becomes 2-D). The change in steepness manifests the same effect described
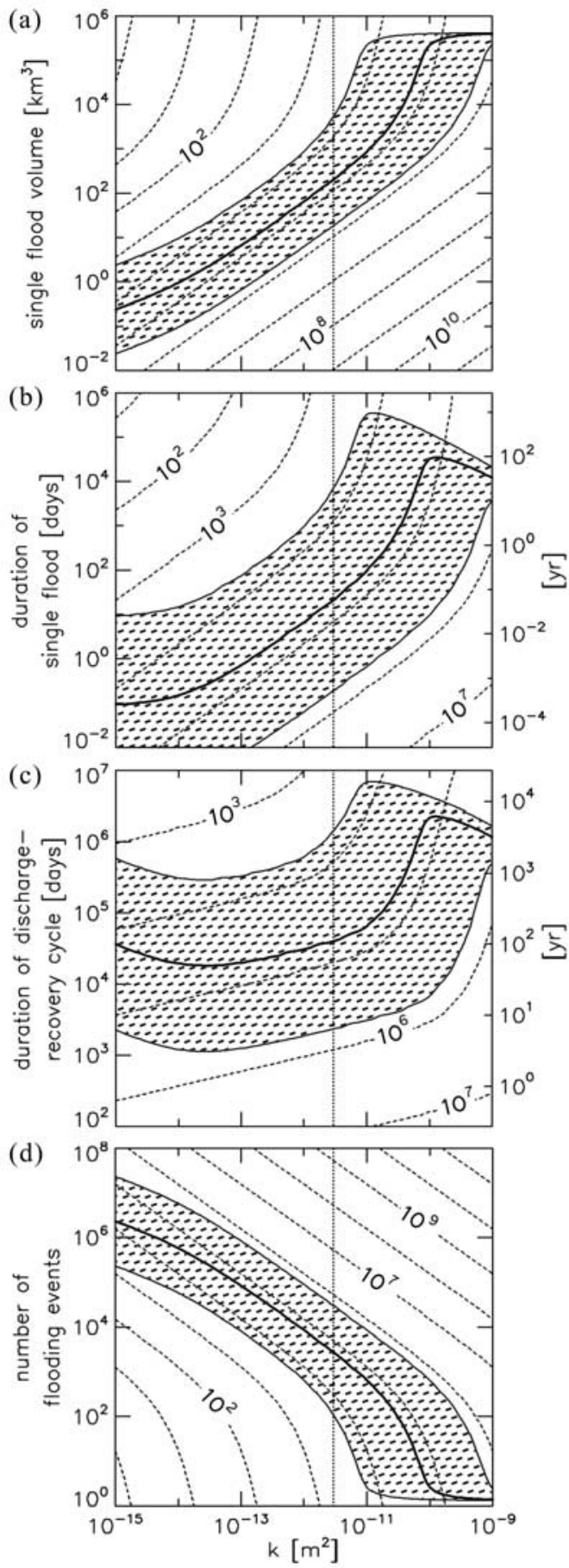


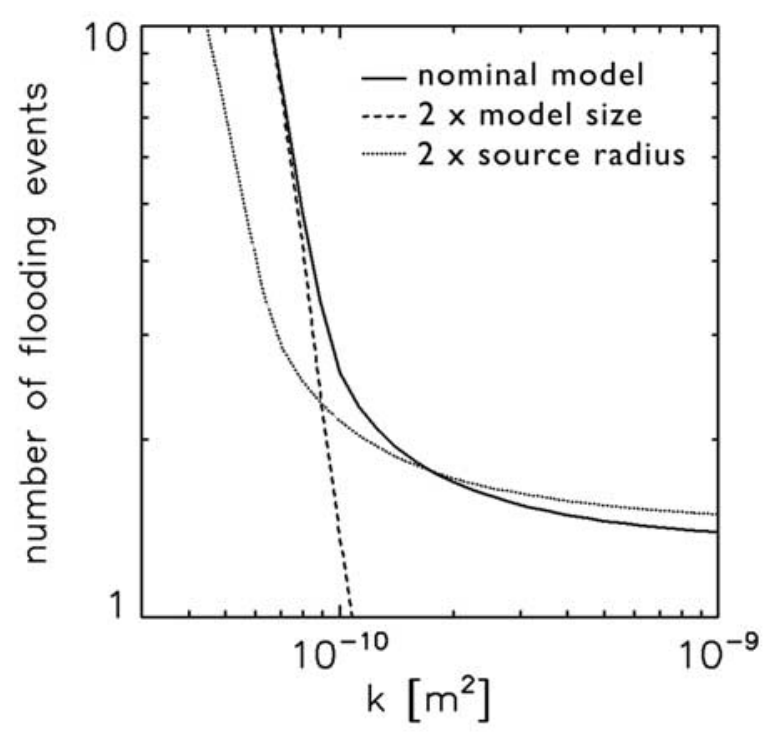

Figure 4. Number of flooding events versus depthaveraged aquifer permeability for nominal model variations. The solid curve is the nominal curve of Figure $3 \mathrm{~d}$ (note change in axis ranges here). The dotted curve indicates a model with twice the source region radius. Higher discharge rates in this model mean that fewer floods are needed, except at higher $k$ where restrictions due to aquifer size dominate. The dashed curve indicates a model with twice the nominal dimensions. Because drawdown reaches the distal boundaries later in this model, attenuation of discharge is delayed and fewer floods are needed. However, the long flood duration needed to let drawdown reach the model boundaries occurs only in models with high $k\left(>8 \times 10^{-11} \mathrm{~m}^{2}\right)$. Increasing aquifer size thus has little influence on aquifers with more reasonable depth-averaged permeabilities.

for Figure 2 but in the opposite sense. The steepening discharge production at high $k$ comes at the expense of time (Figure 3b): discharge from 2-D flow decreases more slowly and so takes longer to drop below the shut-off rate. At high $k$, nominal flood duration reaches a peak of 100 years. While one estimate of Martian channel flood durations supports durations as high as a few years [De Hon et al., 2003], most estimates are on the order of a few to a few 10s of days [e.g., Robinson and Tanaka, 1990; Leask et al., 2006]. These estimates typically assume that high-discharge rates inferred from channel morphology $\left(10^{6}-10^{9} \mathrm{~m}^{3} / \mathrm{s}\right.$ [e.g., Robinson and Tanaka, 1990; Williams et al., 2000]) can be sustained until the required water volume is produced. Taking into account the steeply declining nature of aquifer discharge rate, much longer time intervals are required. However, with the cold atmospheric conditions implicit in the cryosphericdisruption model of outflow channel formation it is unlikely that channel erosion could have been sustained continuously for as long as 100 years.

\subsection{Multiple Flooding Events}

[16] Using a maximum likely S/W of 0.67 [Komar, 1980] and an excavated volume of $3.7 \times 10^{5} \mathrm{~km}^{3}$ for Kasei Valles [Carr, 1996], the minimum required discharge volume is $5.5 \times 10^{5} \mathrm{~km}^{3}$. More than one flooding event is needed to produce this volume (Figure $3 \mathrm{~d}$ ). Although the minimum number of events approaches unity for high $k\left(>10^{-10} \mathrm{~m}^{2}\right)$, suggesting that a single flooding episode may be possible, three factors make such a result unlikely. First, because $k$ represents a depth-averaged value, the most reasonable upper bound is that which corresponds to a near-surface value of $10^{-9} \mathrm{~m}^{2}$, the highest value observed terrestrially [Carr, 1979] and estimated for Mars [MacKinnon and Tanaka, 1989]. Assuming an equatorial cryosphere thickness of $2.8 \mathrm{~km}$ (appendix A), our nominal aquifer thickness of $17 \mathrm{~km}$, and a power law decay of permeability with depth [Manning and Ingebritsen, 1999], a surface permeability of $10^{-9} \mathrm{~m}^{2}$ yields a depth-averaged value of $2.7 \times 10^{-12} \mathrm{~m}^{2}$ (Figure 3). Our nominal model at this permeability requires 2900 flooding events, each lasting 20 days and producing $190 \mathrm{~km}^{3}$ of water. Although the values of $Q_{s}$ used here may be considered lower bounds (appendix A1), we, nonetheless, consider an order of magnitude leeway on either side of the nominal value, yielding 130 and 31,000 as respective lower and upper bounds on the minimum number of flooding events required. The second factor making it difficult to produce outflow channel incision with a single flood is that even if depth-averaged permeabilities can be increased above the likely maximum of $2.7 \times 10^{-12} \mathrm{~m}^{2}$, the duration of individual flooding events becomes unrealistically high, as discussed in section 3.2. Thirdly, we have chosen the maximum likely $\mathrm{S} / \mathrm{W}$. Time-averaged values are likely smaller, implying that greater volumes of water are required to remove the necessary volume of channel material. Delivery of higher water volumes requires more flooding events.

\subsubsection{Limits on Aquifer Size}

[17] Extreme permeabilities by definition are not close to the global average and are limited to the local or regional scale. The relatively high permeabilities of our regional model are therefore likely to be limited spatially. The lateral scale of permeability variations on Mars is unknown but if correlated with photogeologic units would be on the order of $1400 \mathrm{~km}$ (average diameter of units in mapping from Scott and Tanaka [1986], Greeley and Guest [1987], and Tanaka and Scott [1987]). The $2000 \mathrm{~km}$ diameter of our regional model is therefore a suitable average upper bound on the size of a single highly permeable aquifer. The inflection at $k=10^{-10} \mathrm{~m}^{2}$ in the curves of Figure 3 is due to this limit. If no such limit existed, the water volume of a single flood would continue to increase with $k$ (dotted lines of Figure 3a), and the required number of floods would drop rapidly to 1. (Indeed, Carr's [1979] model, which does not apply limits on aquifer size, shows that a single event is possible at high $k$.)

[18] Although our model aquifer dimensions are suitable average upper bounds, the location of the circum-Chryse outflow channels on or close to the highly fractured Tharsis rise suggests they may have had access to a somewhat larger high-permeability aquifer. In order to test the sensitivity of our results to an increase in aquifer size we double the lateral dimensions to $4000 \mathrm{~km}\left(65^{\circ}\right.$ along the equator), keeping the source region dimensions fixed. Drawdown takes longer to reach the model boundaries, thereby extending the discharge period. However, cryosphere fracture refreezing occurs in most models before drawdown reaches model boundaries. The increase in aquifer size therefore affects only those models with already long flood durations, namely those with high $k$ only (Figure 4 ). Indeed, for nominal 
Table 1. Estimates of the Minimum Number of Floods Required to Incise Circum-Chryse Outflow Channels

\begin{tabular}{|c|c|c|c|}
\hline $\begin{array}{l}\text { Outflow Channel } \\
\text { System }\end{array}$ & $\begin{array}{c}\text { Source Region Area, } \\
10^{3} \mathrm{~km}^{2}\end{array}$ & $\begin{array}{c}\text { Excavated Volume, } \\
10^{3} \mathrm{~km}^{3}\end{array}$ & $\begin{array}{c}\text { Minimum Number } \\
\text { of Events }^{\mathrm{c}}\end{array}$ \\
\hline \multicolumn{4}{|l|}{ Ares } \\
\hline Lower bound & 83 (Margaritifer, Iani, and Aram) & 110 (Ares) & 160 \\
\hline Upper bound & 20 (Margaritifer) & 110 (Ares) & 660 \\
\hline Juventae & 4.8 (Juventae) & 33 (Maja) & 830 \\
\hline Kasei & 15 (Echus) & 370 (Kasei) & 2900 \\
\hline Shalbatana & 5.0 (Shalbatana) & 45 (Shalbatana) & 1100 \\
\hline \multicolumn{4}{|l|}{ Simud/Tiu } \\
\hline Lower bound & $\begin{array}{l}210 \text { (Eos/Capri, Aurorae, Hydraotes, } \\
\text { Hydaspis, and Ganges) }\end{array}$ & 460 (Simud, and Tiu) & 270 \\
\hline Upper bound & 64 (Eos/Capri) & 460 (Simud, and Tiu) & 870 \\
\hline
\end{tabular}

$Q_{s}$ and $k=2.7 \times 10^{-12} \mathrm{~m}^{2}$ the minimum number of events required is 2900 , unchanged from the nominal model. Furthermore, if higher $k$ were possible and discharge volume requirements could be met by a single flood, this flood would have to last between 140 and 330 years.

\subsubsection{Duration of Flooding Cycles}

[19] The duration of the recovery phase in a given flooding cycle tends to be significantly greater than that of the discharge phase. We quantify this observation with a plot of total cycle time (Figure 3c) which may be compared to the duration of the discharge phase alone. For the nominal model at the maximum likely permeability of $2.7 \times 10^{-12} \mathrm{~m}^{2}$ the flood cycle duration is 110 years, while the flood itself lasts only 20 days.

[20] Recovery times may be influenced by our global model assumption that a single chaos source region is active. If multiple circum-Chryse outflow channels were simultaneously active, recharge would be divided between sources, causing head to recover more slowly to lithostatic values between floods. The required number of floods would remain unchanged.

\subsubsection{Chaos Radius}

[21] The diameters of large circum-Chryse outflow channel source regions vary from $100 \mathrm{~s}$ to $1000 \mathrm{~s}$ of $\mathrm{km}$. Source regions may thus have diameters up to a few times that of our nominal source $(140 \mathrm{~km})$. To investigate the sensitivity of multiple flooding results to chaos size, we double the chaos radius, keeping other model dimensions the same. The minimum number of floods at high $k$ is controlled by the spatial constraints on hydrologic connectivity and is therefore largely unaffected by changes in source region radius (Figure 4): the slight observed increase is due to the small aquifer volume lost to the expanded source region. At lower $k$, cryosphere fracture refreezing occurs before hydrologic connectivity is exhausted, and a decrease in the required number of events is observed (Figure 4). This decrease varies from a factor of 2 (for models in which flow is terminated while still 1-D and therefore depends on source region circumference) to 4 (flow is 2-D and depends on drawdown area). For our likely maximum $k\left(2.7 \times 10^{-12} \mathrm{~m}^{2}\right)$ the minimum number of floods required is 720 , with respective lower and upper bounds of 33 and 7800.
[22] In order to assess the requirements of other circumChryse outflow channels we scale the minimum number of flooding events for the nominal model $n_{0}$ as follows:

$$
n=n_{0} \frac{A_{0}}{A} \frac{V}{V_{0}},
$$

where $A$ is source region area and $V$ is the volume of material excavated by channel erosion due to groundwater discharge at the source region. Symbols with a "0" subscript represent nominal model values (see entry for Kasei in Table 1). By using $A / A_{0}$ we assume that flow is predominantly 2-D, allowing the maximum decrease in the number of flooding events in response to an increase in source region area. Because it is not always clear which source regions contribute to an individual channel, we calculate lower and upper bounds for $n$ using straightforward end-member assumptions where necessary (Table 1). Because hydraulic head is limited by lithostatic values, initial head gradients for other sources are not likely to vary significantly from the nominal value, and we do not include scaling for this parameter. Our conclusion from Table 1 is that at least a few hundred events are required for each major source-channel system. The excavated volumes of the large outflow channels differ by at most 1 order of magnitude [Carr, 1996], as do the areas of their source regions, and the range of Table 1 values reflects this relatively narrow spread. If we use in equation (1) the lower limit on $n$ (130), the corresponding minimum number of events for other circum-Chryse channels ranges from 8 to 80 . If we use the upper limit on $n(31,000)$, the minimum number of events for other channels ranges from 1700 to 19,000 .

\section{Discussion}

[23] Using regional-scale groundwater models, we find that multiple outflow channel flooding events, sourced directly by aquifer discharge and separated by periods of aquifer resealing because of freezing, most likely number in the $100 \mathrm{~s}$ or $1000 \mathrm{~s}$ to produce the minimum discharge necessary to erode observed outflow channels. It is difficult to constrain observationally the number of flooding events 
that carved the Martian outflow channels. However, even if evidence for $100 \mathrm{~s}$ or $1000 \mathrm{~s}$ of events in a given channel can be found, the number of required events may still be higher. This is due principally to our liberal choice of $\mathrm{S} / \mathrm{W}$ : Estimates for circum-Chryse outflow channels range as low as $10^{-4}$ [De Hon et al., 2003], suggesting the maximum value of 0.67 used for our models may not be typical. Lower $\mathrm{S} / \mathrm{W}$ values require larger volumes of water and therefore an even greater number of events. An additional problem arises if flow freezes in the channels and remains in place over multiple flooding cycles. This will place an upper bound on the time available for channel erosion and therefore on the number of flooding cycles able to do erosional work. Analysis of channel flow timescales under subfreezing conditions has been limited to much smaller Martian features [e.g., Carr, 1983; Heldmann et al., 2005] and is beyond the scope of the current work.

\section{Ponding}

[24] For cases in which the predicted minimum number of flooding events is unreasonably high we suggest that an alternative mechanism for floodwater delivery is required. While groundwater discharge at chaotic terrain may indeed have occurred as frequently as predicted by our model results, we suggest it did not provide a direct source of channel flow but ponded locally and produced standing bodies of water either on the surface or in voids in the shallow subsurface. This mechanism has previously been invoked for both small and large outflow channels (Athabasca Vallis [Burr et al., 2002], Kasei Valles [Robinson and Tanaka, 1990], and Maja Vallis [Coleman and Baker, 2007]). Once standing bodies grew to a critical volume they failed, rapidly delivering large volumes of water to the downstream surface, causing outflow channel incision. Failure may have occurred in the manner of Icelandic jökulhlaups, i.e., through disruption of ice dams due to melting, increased water pressure, or entry into the lake of a landslide, avalanche, or ice mass [Chapman and Tanaka, 2002]. Rocky dams might have failed through soil failure induced by increased fluid pore pressures. Additionally, subsurface bodies may have emptied to the surface through roof and wall collapse.

[25] Failure of ice dams and subsequent channel formation is thought to have occurred terrestrially in the Channeled Scablands of Washington State [Bretz et al., 1956] where the closest analog to the Martian outflow channels is observed. Here several 10s of flooding events [Benito and O'Connor, 2003] occurred as a result of ice dam melting near the end of the Pleistocene period of glaciation. The resulting channels are several $\mathrm{km}$ wide and $10 \mathrm{~s}-100 \mathrm{~s}$ of $\mathrm{km}$ long and exhibit many of the same flow features as the Martian channels. Large-scale flooding may also have accompanied the failure of a large glacial lake (Lake Agassiz) occupying the Great Lakes region of North America [Fisher, 2004].

[26] The ponding of water serves as a buffer whereby frequent, but relatively small discharge volumes from confined aquifers are able, over $100 \mathrm{~s}$ to $1000 \mathrm{~s}$ of years, to build large localized sources of water capable of forming outflow channels with just a few tens of catastrophic outburst events. The buffering effect also applies to discharge rates. Although discharge in our numerical models can (as dis- cussed in section 1) be made to occur at arbitrarily high initial rates, it declines rapidly to rates lower than those inferred for Martian outflow channels on a timescale of at most an hour. More typically, timescales are on the order of a second or less, and the discharge period of a flooding event is dominated by orders of magnitude lower discharge rates. This brings into doubt the ability of groundwater floods to produce the large erosive forms observed in the outflow channels. A large standing body of water may, depending on the nature of the breach allowing it to drain, be able to maintain high discharge rates for longer periods (hours or days).

[27] Ponded bodies would need to remain at least partially unfrozen in order to provide water for channel incision. Freezing time for a lake a few $100 \mathrm{~m}$ deep is likely to be on the order of a few 1000 years under present climatic conditions [Kreslavsky and Head, 2002], long enough to produce a flood for every few 10 s of groundwater discharge events (Figure $3 \mathrm{c}$ ). Considering our nominal model prediction of 2900 discharge events, several 10s of lake failures would be required. This range is compatible with that inferred from terrestrial megaflood channels sourced by failed ice dam discharge [Benito and O'Connor, 2003]. Nonetheless, some ice may need to be melted by local heat sources: a possible candidate is volcanism, as suggested by evidence of magma-ice interactions in some chasmata and chaotic terrains [Chapman and Tanaka, 2002; Chapman et al., 2003; Cabrol et al., 1997].

[28] Although a detailed account of evidence for ponding at chaos regions is beyond the scope of this paper, it behooves us to provide some preliminary observations and also to address possible contradictory evidence. Chaotic terrain is frequently found in local topographic basins, with nearby channel head regions located above the deepest point of the basin. A simple analysis of gridded MOLA data shows that most of the major chaos regions exhibit this topographic relationship, including Juventae, Shalbatana, Ravi, Capri, Hydraotes, Hydaspis, Aram, Iani, and Margaritifer chaotic terrain (Figure 5). Although some depressions appear to have developed or deepened as a direct result of chaotic terrain formation, implying that only later floods would have ponded, other basins appear to have tectonic or impact cratering origins and likely existed before chaos formation. Subsequent burial of chaotic terrain may also have occurred, causing original depression depths to be underestimated. For instance, the Echus Chasma floor is approximately $200 \mathrm{~m}$ below the head of Kasei Valles but, nonetheless, appears to have been inundated by a hydrostatically equilibrated deposit interpreted by Witbeck et al. [1991] as locally derived alluvial or aeolian material of Amazonian age. Floor elevations vary by less than $50 \mathrm{~m}$ over a span of some $150 \mathrm{~km}$ and are $3 \mathrm{~km}$ higher than the deepest point in neighboring Hebes Chasma, suggesting a considerably deeper depression prior to inundation (Figure 6). Further north relatively young Tharsis Montes lava flows appear to have covered the head regions of Kasei Valles [Greeley and Guest, 1987], suggesting it too was deeper during channel formation.

[29] Terraces encircling chaotic blocks and lining chasma walls may be paleolake shoreline features, providing further evidence of ponding. Examples are found in Hydraotes Chaos [Ori and Mosangini, 1998] and Coprates Chasma 


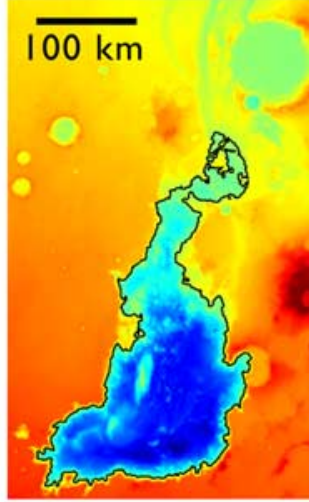

Juventae Chasma $4600 \mathrm{~m}$

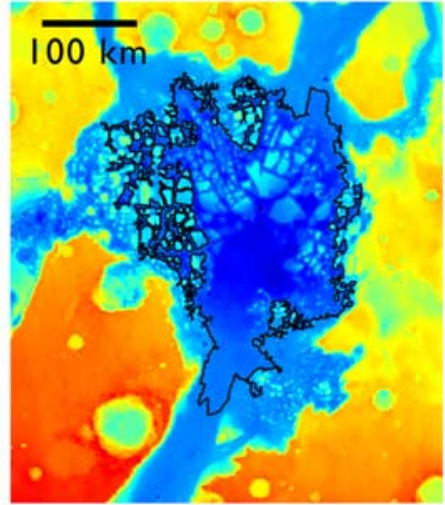

Hydraotes Chaos $1500 \mathrm{~m}$

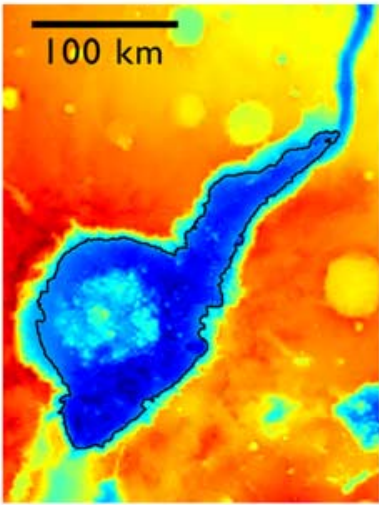

Shalbatana Chaos $1600 \mathrm{~m}$

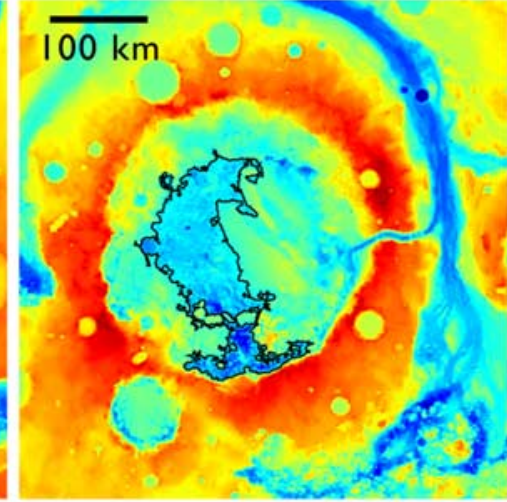

Aram Chaos

$1200 \mathrm{~m}$

Figure 5. Examples of chaos regions in topographic depressions. Black contours give the approximate ponding level above which water would begin to spill over into adjacent channels. The maximum depth of ponded bodies corresponding to these contours is given below each chaos name. Colors correspond to gridded MOLA topography and are scaled differently in each image.

[Harrison, 2007]. In the latter example the volume of the putative paleolake is $1.1 \times 10^{5} \mathrm{~km}^{3}$, only three times smaller than the volume required for erosion of a large outflow channel such as Simud Vallis (assuming high S/W [Carr, 1996]).

[30] Evidence also exists for subsurface void spaces. Large collapse features are observed between Ganges Chasma and Shalbatana Chaos [Carr, 1996] and in Ganges Chasma itself [Rodriguez et al., 2006]. These spaces may have contained water in standing bodies rather than in small, diffusely distributed pores [Rodriguez et al., 2005].

[31] Possible evidence against ponding at chaotic terrain lies in the apparent dearth of mineralogic evidence collected to date. For instance, the putative lakes in Coprates and Hydraotes Chasmata show no evidence of water-related minerals such as sulfates and phyllosilicates [Bibring et al., 2006]. Also, olivine (which is unstable in aqueous conditions) is found in high concentrations in basaltic outcroppings in some Chryse Planitia channels [Christensen et al., 2003; Edwards et al., 2007].

[32] The absence of phyllosilicates is not unexpected. These minerals are thought to have formed predominantly in the Noachian (the "phyllosian") before outflow channel formation and the proposed surface ponding. In addition, phyllosilicates are generally not found in association with lacustrine environments (with the notable exception of Holden Crater [Milliken et al., 2007]). Sulfates, on the other hand, are observed in several locations in the Valles Marineris and Chryse Planitia regions and may actually support ponding there [Gendrin et al., 2005]. Because they are closely associated with freshly exhumed scarps in interior layered deposits, their absence from gently sloping and dust-mantled lake floors in Coprates and Hydraotes Chasmata seems reasonable. Ultimately though, alternative processes such as groundwater alteration or ice-magma interactions may explain both the sulfates and the interior layered deposits [Gendrin et al., 2005; Chapman and Tanaka, 2002]. In this case the absence of sulfates during subsequent lake formation may be the result of unfavorable mineralogic and thermal conditions. Finally, olivine-rich basalts in Chryse Planitia appear to conflict with the occurrence of surface flooding: outcrops occur in channel banks and occasionally on channel floors. Perhaps transient floods are not sufficiently long-lived to produce the weath-
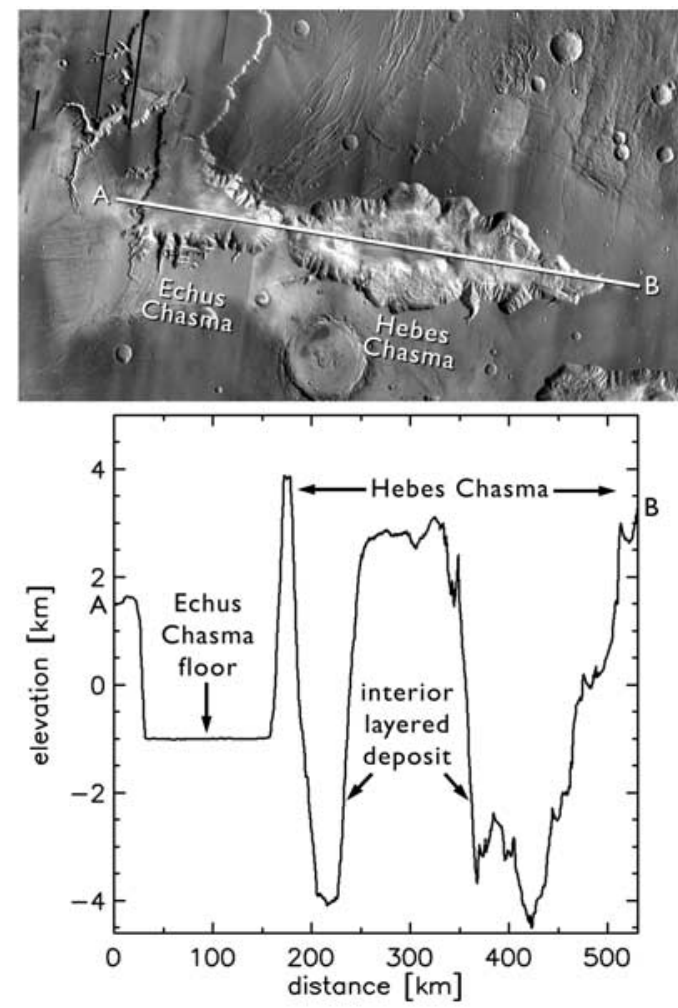

Figure 6. Gridded MOLA elevation profile along the floors of Echus and Hebes Chasmata suggests that the former canyon is filled with a hydrostatically equilibrated deposit, and that its floor may once have been kilometers deeper than at present. (top) Context image is a mosaic of Mars Odyssey Thermal Emissions Imaging System daytime IR images. 
ering necessary to destabilize olivine. Certainly, no outcrops have yet been identified in circum-Chryse chaotic terrain depressions that likely held standing bodies of water [Edwards et al., 2007]. Further study of these deposits and their relationship to the hydrologic history of the region is required to better understand their significance.

\section{Conclusions}

[33] Numerical models of groundwater flow and surface discharge at Martian outflow channel sources indicate that hundreds to thousands of flooding events are needed to erode the large circum-Chryse outflow channels. For our nominal model of the Kasei Valles source region a maximum likely depth-averaged aquifer permeability of $2.7 \times$ $10^{-12} \mathrm{~m}^{2}$ (corresponding to a near surface value of $10^{-9}$ $\mathrm{m}^{2}$ ) yields a minimum of 2900 floods, each lasting approximately 20 days and transporting $190 \mathrm{~km}^{3}$ of water. Model scaling suggests that a minimum of several 100 floods are required to incise other large circum-Chryse channels. Although there are few observational constraints on the number of floods, hundreds to thousands of events are probably unlikely. In this case we suggest that flooding was not caused directly by groundwater discharge. Instead, discharge collected locally over relatively long time periods to form standing bodies of water. These bodies were eventually breached, releasing large floods capable of outflow channel incision. Failure mechanisms include weakening of dams due to pore water saturation and floating or disruption of ice dams. Ponded bodies may have undergone multiple cycles of refilling and catastrophic release, with each refilling stage accomplished by $10 \mathrm{~s}-100 \mathrm{~s}$ of groundwater discharge events.

\section{Appendix A: Cryosphere Fracture Refreezing Time}

[34] Because pore water in the cryosphere is frozen, we assume that fluid transport occurs primarily through fractures associated with chaotic terrain formation. This is in contrast to aquifer porosity which we assume is dominated by the canonical structure of small, interconnected pore spaces. We partition cryosphere fracture refreezing time into two phases delineated by flow regime. In the first phase, flow is turbulent and water is assumed to freeze predominantly in the form of frazil ice [French, 1985] which is carried away by the flow and does not contribute to the restriction of fracture apertures [Andrews-Hanna and Phillips, 2007]. In the second phase, flow becomes laminar, and ice accumulates on fracture walls, eventually blocking the fractures completely.

\section{A1. Turbulent Flow Timescale}

[35] To calculate the turbulent flow timescale, we use the formulation of Andrews-Hanna and Phillips [2007], which determines the discharge rate through cryosphere fractures as flow changes from turbulent to laminar,

$$
Q_{\mathrm{cr}}=\frac{\mu N A}{\rho} R e_{\mathrm{cr}},
$$

where $\mu$ and $\rho$ are fluid viscosity and density, $N$ is fracture density, $A$ is the source region surface area, and $R e_{\mathrm{cr}}$ is the critical Reynolds number delineating laminar and turbulent flow regimes (we use $R e_{\text {cr }}=4000$ ). Cryosphere fracture flow velocity is driven by head gradients in the underlying aquifer and thus decreases with time (Figure 2). The time taken for this velocity to drop below the critical value $Q_{\mathrm{cr}}$ is the turbulent flow timescale and varies with depth-averaged aquifer permeability $k$. To constrain $Q_{\text {cr }}$, we use a likely minimum value of $N\left(0.001 \mathrm{~m}^{-1}\right.$ [Andrews-Hanna and Phillips, 2007]) yielding a minimum $Q_{\text {cr }}$ estimate of $5.8 \times$ $10^{4} \mathrm{~m}^{3} / \mathrm{s}$. Because discharge rate decreases with time, a minimum value corresponds to a maximum turbulent flow duration, which in turn yields an upper bound on the cumulative volume of water produced during the turbulent phase. (As described in section 1, our approach here is to use liberal constraints on discharge production to provide upper bounds on the efficiency of the multiple flood mechanism.) Turbulent flow timescales can be determined for different $k$ by noting where the corresponding curve in Figure 2 falls below $Q_{\text {cr. }}$.

[36] The turbulent flow timescale is not explicitly dependent on fracture aperture. However, aperture plays an important role in the ability of the cryosphere to impede aquifer discharge. To ensure that the cryosphere does not significantly restrict the volume of water produced before refreezing, we consider the turbulent velocity $V$ of water through a fracture, as given by Head et al. [2003],

$$
V=\left[\frac{b}{f_{w} \rho} \frac{d P}{d z}\right]^{1 / 2},
$$

where $b$ is the fracture aperture, $d P / d z$ is the pressure gradient driving the flow, and $f_{w}$ is a friction coefficient (taken here to be 0.025 [French, 1985; Andrews-Hanna and Phillips, 2007]). We use equation (A2) to compute the vertical head difference across the chaos that is required to transport groundwater at the rate dictated by discharge calculations in our numerical models. This head difference must be exerted by pore pressure in the aquifer. If pore pressure is insufficient, the chaos will impede aquifer discharge. Analysis of pressures in our models suggest that a range of apertures of about $0.002-0.05 \mathrm{~m}$ in equation (A2) will result in negligible reduction in cumulative discharge to the surface over the range of permeabilities considered. These values compare favorably with terrestrially observed apertures (e.g., $10^{-4}-10^{-2} \mathrm{~m}$ [Gudmundsson et al., 2001]) and we therefore conclude that fracture flow through the cryosphere does not present significant restrictions on aquifer discharge.

\section{A2. Laminar Flow Timescale}

[37] To investigate that part of the fracture refreezing process characterized by laminar flow, we constructed 1-D Crank-Nicholson thermal models of one half of a vertical fracture and its neighboring wall rock. In this model the left and right boundaries are periodic (zero temperature gradient), simulating an array of similar fractures parallel to each other. The initial temperature of the fracture water is assumed to be just above a freezing point of $252 \mathrm{~K}$ (eutectic of $\mathrm{NaCl}$ brine [Clark and van Hart, 1981]). The initial temperature of the rock is that of the Martian surface (209 K). The cryosphere temperature increases with depth, but freezing occurs fastest near the surface, where the temperature 
contrast between fluid and rock is greatest, and this is where fracture closure begins. A maximum fracture aperture of $0.05 \mathrm{~m}$ (based on the range derived in section A1) yields a freezing time of $125 \mathrm{~min}$. This value is generally short compared to the turbulent timescale, but if narrower fracture apertures are considered, turbulent and laminar timescales decrease such that the latter begins to dominate.

[38] Because thermal conduction and groundwater flow are both diffusional processes, the recovery phase of the model will allow temperature to recover commensurately with hydraulic head. Thus the thermal history of fracture refreezing can, as with the hydraulic head history, be assumed to be repeatable without further explicit modeling. However, there is an important exception: the space adjacent to a given fracture may be influenced by the thermal evolution of the neighboring fracture. If two fractures are close enough, the rock between them may be heated to such an extent that it remains significantly warmed at the end of the recovery phase. The subsequent discharge phase will have a different thermal history from the last, and after a few discharge-recovery cycles the wall rock may reach a steady temperature high enough to eschew refreezing of fracture water altogether. Discrete floods give way to continuous discharge, and the hydraulic head tends toward the same solution as the global model used to impose the boundary conditions. Experiments with our thermal model indicate that effective fracture porosities lower than about 0.01 will ensure a repeat of refreezing and discrete events. The fracture densities and apertures given in section A1. correspond to fracture porosities well below this value, peaking at 0.001 . The contrast between these porosities and that of the aquifer $(0.02)$ is balanced by the different types of flow in each medium, i.e., fracture flow in the cryosphere and diffusional porous medium flow in the aquifer.

[39] To conclude, we describe how the laminar and turbulent timescales are combined in order to find the shut-off discharge rate $Q_{s}$ for a particular $k$. The laminar timescale is the nominal $125 \mathrm{~min}$ derived above, while the turbulent timescale corresponds to the time at which the appropriate discharge curve in Figure 2 drops below a discharge rate of $Q_{\mathrm{cr}}\left(5.8 \times 10^{4} \mathrm{~m}^{3} / \mathrm{s}\right)$. The sum of the two time intervals is then used with the same Figure 2 curve to obtain $Q_{s}$.

\section{Appendix B: Cryosphere Transit Time}

[40] Consideration of fracture refreezing time raises a related issue, namely the finite time taken for discharge to flow from the base of the cryosphere to the surface. For surface and melting temperatures of 209 and $252 \mathrm{~K}$, a Hesperian crustal heat flux of $30 \mathrm{~mW} / \mathrm{m}^{2}$ [Harrison and Grimm, 2004], and a thermal conductivity of $2 \mathrm{~W} \mathrm{~m}^{-1} \mathrm{~K}^{-1}$, the equatorial cryosphere thickness is $2.8 \mathrm{~km}$. We consider the total distance $d$ traveled by the flow through the cryosphere fractures before refreezing occurs and compare this value to the cryosphere thickness. Distances are calculated by integrating over time the fracture velocity corresponding to the source region discharge rate $Q$,

$$
d(k)=\frac{1}{A b N} \int_{0}^{t 0} Q(k, t) d t,
$$

where $t_{0}$ is the refreezing time. We adopt a range of apertures covering the same orders of magnitude considered in section A1 $\left(10^{-3}-10^{-2} \mathrm{~m}\right)$. At $k<10^{-14} \mathrm{~m}^{2}$ and $b=$ $10^{-2} \mathrm{~m}, d$ is comparable to cryosphere thickness. However, for the vast majority of $k$ and $b$ values, $d$ exceeds cryosphere thickness by orders of magnitude, and we conclude generally that discharge reaches the surface.

[41] Acknowledgments. This work was supported by NASA grant NNG05GL22G. Thanks to Nathalie Cabrol and Jeff Andrews-Hanna for valuable and productive reviews and to Amy Barr, Mark Bullock, and David Stillman for helpful feedback and discussion.

\section{References}

Andrews-Hanna, J. C., and R. J. Phillips (2007), Hydrological modeling of outflow channels and chaos regions on Mars, J. Geophys. Res., 112, E08001, doi:10.1029/2006JE002881.

Baker, V. R. (1979), Erosional processes in channelized water flows on Mars, J. Geophys. Res., 84, 7985-7993.

Benito, G., and J. E. O'Connor (2003), Number and size of last-glacial Missoula floods in the Columbia River valley between the Pasco Basin, Washington, and Portland, Oregon, Geol. Soc. Am. Bul1., 115, 624-638.

Bibring, J.-P., et al. (2006), Global mineralogical and aqueous Mars history derived from OMEGA/Mars Express data, Science, 312, 400-404.

Binder, A. B., and M. A. Lange (1980), On the thermal history, thermal state, and related tectonism of a Moon of fission origin, J. Geophys. Res., $85,3194-3208$.

Bretz, J. H., H. T. U. Smith, and G. E. Neff (1956), Channeled Scabland of Washington: New data and interpretations, Geol. Soc. Am. Bull., 67, 957-1049.

Burr, D. M., J. A. Grier, A. S. McEwen, and L. P. Keszthelyi (2002), Repeated aqueous flooding from the Cerberus Fossae: Evidence for very recently extant, deep groundwater on Mars, Icarus, 159, 53-73.

Cabrol, N. A., E. A. Grin, and G. Dawidowicz (1997), A model of outflow generation by hydrothermal underpressure drainage in volcano-tectonic environment, Shalbatana Vallis (Mars), Icarus, 125, 455-464.

Carr, M. H. (1979), Formation of Martian flood features by release of water from confined aquifers, J. Geophys. Res., 84, 2995-3007.

Carr, M. H. (1983), Stability of streams and lakes on Mars, Icarus, 56, $476-495$

Carr, M. H. (1996), Water on Mars, Oxford Univ. Press, New York.

Chapman, M. G., and K. L. Tanaka (2002), Related magma-ice interactions: Possible origins of chasmata, chaos, and surface materials in Xanthe, Margaritifer, and Meridiani Terrae, Mars, Icarus, 155, 324-339.

Chapman, M. G., M. T. Gudmundsson, A. J. Russell, and T. M. Hare (2003), Possible Juventae Chasma subice volcanic eruptions and Maja Valles ice outburst floods on Mars: Implications of Mars Global Surveyor crater densities, geomorphology, and topography, J. Geophys. Res., 108(E10), 5113, doi:10.1029/2002JE002009.

Christensen, P. R., et al. (2003), Mars: Mars Odyssey THEMIS results, Science, 300, 2056-2061.

Clark, B. C., and D. C. van Hart (1981), The salts of Mars, Icarus, 45, 370378 .

Clifford, S. M. (1993), A model for the hydrologic and climatic behavior of water on Mars, J. Geophys. Res., 98, 10,973-11,016.

Coleman, N. M. (2005), Martian megaflood-triggered chaos formation, revealing groundwater depth, cryosphere thickness, and crustal heat flux, J. Geophys. Res., 110, E12S20, doi:10.1029/2005JE002419.

Coleman, N. M., and V. Baker (2007), Evidence that a paleolake overflowed the rim of Juventae Chasma, Mars, paper 1046 presented at 38th Lunar and Planetary Science Conference, Lunar and Planet. Inst., Houston, Tex.

De Hon, R. A., P. A. Washington, and C. J. Thibodeaux (2003), Excavation time for the Vedra and Maumee channels (Mars) by application of equilibrium sediment theory, paper 1178 presented at 34th Lunar and Planetary Science Conference, Lunar and Planet. Inst., Houston, Tex.

Edwards, C. S., P. R. Christensen, and V. E. Hamilton (2007), Evidence for extensive olivine-rich basalt bedrock outcrops in Ganges and Eos chasma on Mars, paper 3280 presented at 7th International Conference on Mars, Lunar and Planet. Inst., Pasadena, Calif.

Fisher, T. G. (2004), River Warren boulders, Minnesota, USA: Catastrophic paleoflow indicators in the southern spillway of glacial Lake Agassiz, Boreas, 33, 349-358.

French, R. H. (1985), Open-Channel Hydraulics, 739 pp., McGraw-Hill, New York.

Gendrin, A., et al. (2005), Sulfates in Martian layered terrains: The OMEGA/ Mars Express view, Science, 307, 1587-1591. 
Glotch, T. D., and P. R. Christensen (2005), Geologic and mineralogic mapping of Aram Chaos: Evidence for a water-rich history, J. Geophys. Res., 110, E09006, doi:10.1029/2004JE002389.

Greeley, R., and J. E. Guest (1987), Geologic map of the eastern equatorial region of Mars, scale 1:15,000,000, U.S. Geol. Surv. Misc. Invest. Map, I- $1802 B$.

Gudmundsson, A., S. Berg, K. Lyslo, and E. Skurtveit (2001), Fracture networks and fluid transport in active fault zones, J. Struct. Geol., 23, $343-353$.

Hanna, J. C., and R. J. Phillips (2003), Theoretical modeling of outflow channels and chaos regions on Mars, Eos Trans. AGU, 84(46), 2003 Fall AGU Meet. Suppl., F933.

Hanna, J. C., and R. J. Phillips (2005), Hydrological modeling of the Martian crust with application to the pressurization of aquifers, J. Geophys. Res., 110, E01004, doi:10.1029/2004JE002330.

Harbaugh, A. W., E. R. Banta, M. C. Hill, and M. G. McDonald (2000), MODFLOW-2000, the U.S. Geological Survey modular ground-water model: User guide to modularization concepts and the ground-water flow process, U.S. Geol. Surv. Open File Rep., 00-92.

Harrison, K. P. (2007), Ponding in central Valles Marineris due to late-stage Martian outflow channel activity, paper 1806 presented at 38th Lunar and Planetary Science Conference, Lunar and Planet. Inst., Houston, Tex.

Harrison, K. P., and R. E. Grimm (2004), Tharsis recharge: A source of groundwater for Martian outflow channels, Geophys. Res. Lett., 31, L14703, doi:10.1029/2004GL020502.

Head, J. W., L. Wilson, and K. L. Mitchell (2003), Generation of recent massive water floods at Cerberus Fossae, Mars by dike emplacement, cryospheric cracking, and confined aquifer groundwater release, Geophys. Res. Lett., 30(11), 1577, doi:10.1029/2003GL017135.

Heldmann, J. L., O. B. Toon, W. H. Pollard, M. T. Mellon, J. Pitlick, C. P. McKay, and D. T. Andersen (2005), Formation of Martian gullies by the action of liquid water flowing under current Martian environmental conditions, J. Geophys. Res., 110, E05004, doi:10.1029/2004JE002261.

Komar, P. D. (1980), Modes of sediment transport in channelized water flows with ramifications to the erosion of the Martian outflow channels, Icarus, 42, 317-329.

Kreslavsky, M. A., and J. W. Head (2002), Fate of outflow channel effluents in the northern lowlands of Mars: The Vastitas Borealis Formation as a sublimation residue from frozen ponded bodies of water, J. Geophys. Res., 107(E12), 5121, doi:10.1029/2001JE001831.

Leask, H. J., L. Wilson, and K. L. Mitchell (2006), Formation of Aromatum Chaos, Mars: Morphological development as a result of volcano-ice interactions, J. Geophys. Res., 111, E08071, doi:10.1029/2005JE002549.

Lohman, S. W. (1972), Ground-water hydraulics, U.S. Geol. Surv. Prof. Pap., 708,70 p.

MacKinnon, D. J., and K. L. Tanaka (1989), The impacted Martian crust: Structure, hydrology, and some geologic implications, J. Geophys. Res. 94, 17,359-17,370.

Manga, M. (2004), Martian floods at Cerberus Fossae can be produced by groundwater discharge, Geophys. Res. Lett., 31, L02702, doi:10.1029/ 2003GL018958.
Manning, C. E., and S. E. Ingebritsen (1999), Permeability of the continental crust: Implications of geothermal data and metamorphic systems, Rev. Geophys., 37(1), 127-150.

Milliken, R. E., J. P. Grotzinger, S. Murchie, J. A. Grant, and the CRISM team (2007), Evidence for hydrated phyllosilicates in Holden Crater, Mars using hyperspectral CRISM data, paper 1913 presented at 38th Lunar and Planetary Science Conference, Lunar and Planet. Inst., Houston, Tex.

Ori, G. G., and C. Mosangini (1998), Complex depositional systems in Hydraotes Chaos, Mars: An example of sedimentary process interactions in the Martian hydrologic cycle, J. Geophys. Res., 103, 22,713-22,723.

Robinson, M. S., and K. L. Tanaka (1990), Magnitude of a catastrophic flood event at Kasei Valles, Mars, Geology, 18, 902-905.

Rodriguez, J. A. P., S. Sasaki, R. O. Kuzmin, J. M. Dohm, K. L. Tanaka, H. Miyamoto, K. Kurita, G. Komatsu, A. G. Fairén, and J. C. Ferris (2005), Outflow channel sources, reactivation, and chaos formation, Xanthe Terra, Mars, Icarus, 175, 36-57.

Rodriguez, J. A. P., J. Kargel, D. A. Crown, L. F. Bleamaster III, K. L. Tanaka, V. Baker, H. Miyamoto, J. M. Dohm, S. Sasaki, and G. Komatsu (2006), Headward growth of chasmata by volatile outbursts, collapse, and drainage: Evidence from Ganges chaos, Mars, Geophys. Res. Lett., 33 , L18203, doi:10.1029/2006GL026275.

Saar, M. O., and M. Manga (1999), Permeability-porosity relationship in vesicular basalts, Geophys. Res. Lett., 26, 111-114.

Scott, D. H. (1993), Geologic map of the MTM 25057 and 25052 quadrangles, Kasei Valles region of Mars, scale 1:500,000, U.S. Geol. Surv Misc. Invest. Map, I-2208.

Scott, D. H., and K. L. Tanaka (1986), Geologic map of the western equatorial region of Mars, scale 1:15,000,000, U.S. Geol. Surv. Misc. Invest Map, I-1802A.

Tanaka, K. L., and D. H. Scott (1987), Geologic map of the polar regions of Mars, scale 1:15,000,000, U.S. Geol. Surv. Misc. Invest. Map, I-1802C.

Tanaka, K. L., and J. A. Skinner (2004), Advances in reconstructing the geologic history of the Chryse region outflow channels on Mars, paper 1770 presented at 35th Lunar and Planetary Science Conference, Lunar and Planet. Inst., Houston, Tex.

Williams, R. M. E., and M. C. Malin (2004), Evidence for late stage fluvial activity in Kasei Valles, Mars, J. Geophys. Res., 109, E06001, doi:10.1029/2003JE002178.

Williams, R. M. E., R. J. Phillips, and M. C. Malin (2000), Flow rates and duration within Kasei Valles, Mars: Implications for the formation of a Martian ocean, Geophys. Res. Lett., 27, 1073-1076.

Witbeck, N. E., K. L. Tanaka, and D. H. Scott (1991), Geologic map of the Valles Marineris region, Mars, U.S. Geol. Surv. Misc. Invest. Map, I-2010.

R. E. Grimm and K. P. Harrison, Southwest Research Institute, 1050 Walnut Street, Suite 300, Boulder, CO 80302, USA. (harrison@boulder. swri.edu) 